\title{
Reflexões sobre a aprendizagem através da prototipagem no projeto de produto
}

Allyneanhy Gade Nunes Alves Oliveira

resumo:

A prototipagem cumpre o papel de contribuir com o aprendizado do designer, visto que através dessa etapa há grande evolução no projeto. Um designer ou estudante de Design muitas vezes almeja obter uma resposta imediata em seus projetos, esperando que os protótipos sejam realizados com perfeição, mas se frustram por geralmente não saírem como previstos. Nesse sentido, o presente artigo reflete sobre a aprendizagem obtida por meio da prototipagem no projeto de produto, em meio aos fenômenos diversos que ocorrem durante o processo. Para contribuir ao estudo, é apresentado o trabalho elaborado ao longo da disciplina de Projeto de Produto 4 do curso em Design, que representa a exemplificação da temática: o projeto de mobiliário urbano. Os resultados discutidos no artigo levaram à conclusão de que os fenômenos ocorridos na prototipagem conduzem à novas informações a serem consideradas e que moldam as decisões necessárias ao projeto, obtendo seus requisitos.

palavras-chave:

Protótipo; Projeto; Aprendizagem; Design 


\section{Introdução}

O início da Revolução Industrial teve seu papel importante no surgimento dos protótipos. O projetista buscava elaborar o produto experimental na fase anterior ao lançamento e à fabricação em série dos artefatos. Por conseguinte, o protótipo foi tornando-se uma etapa necessária no desenvolvimento de projetos que, portanto, consiste em ser uma solução física do projeto.

Segundo Mike Baxter (2000), "o protótipo significa literalmente, o primeiro de um tipo". Baxter (2000) ainda cita que o termo é atribuído a dois tipos de representações dos produtos, sendo o primeiro direcionado à representação física do artefato, tornando este possível de ser produzido industrialmente. Já o segundo, compreende o significado amplo do termo, cumprindo a função de representação física construída para a realização de testes físicos. Coelho (2008, p.140) foi objetivo ao afirmar que o protótipo vem do termo em latim prototypus, carregando em si o significado de primeiro tipo (proto-tipo), uma criação original ou primária, e quando lançada como cópia ou reprodução, é denominada como modelo.

O Design possui caráter experimental e prático. Suas atividades envolvem a busca por soluções que vão além do campo conceitual, mas em visualizar as ideias geradas através de representações físicas. Nesse sentido, o uso de protótipo no projeto fornece a representação semelhante ao real. Contudo, é possível entender que usualmente os protótipos não surgem de início como as soluções perfeitas que os designers esperam, o que culmina em mais experimentações, feedbacks e melhorias destes até que se transformem na solução esperada e definitiva.

Ainda que a prototipagem seja uma experiência utilizada por muitos designers, alunos de design ou projetistas, a busca por aprender através dos erros e acertos na realização de protótipos é por vezes desconsiderada. Porém, a prototipagem é um estágio necessário no processo de desenvolvimento de produto no qual se verifica se este atende aos requisitos dos usuários e funciona com as devidas expectativas. Ademais, as atividades práticas de prototipagem auxiliam na obtenção de conhecimento latente sobre fenômenos complexos (TELENKO et al., 2015).

$\mathrm{O}$ artigo presente tem como objetivo refletir por meio de uma experimentação realizada, que os fenômenos ocorridos na prototipagem de produto produzem novos aprendizados. Tais circunstâncias levam o designer ou estudante de design às melhorias do projeto. Nesse sentido, esse olhar crítico e reflexivo ao protótipo torna-se um tema de contribuição à comunidade acadêmica e aos profissionais de Design.

$\mathrm{Na}$ estrutura do artigo, a revisão de literatura aborda os conceitos e definições da prototipagem, sua relação com as teorias de aprendizagem e a reflexão sobre a ação projetual que o designer precisa considerar. O tópico da metodologia, descreve os procedimentos utilizados como pesquisa bibliográfica e o estudo de caso, em que envolveram experimentações no projeto elaborado em disciplina acadêmica, e demonstrando bem a temática em questão.

Dessa maneira, o tópico dos resultados trouxera o projeto realizado na disciplina Projeto de Produto 4, no $6^{\circ}$ semestre do curso de Design na UFC (Universidade Federal do Ceará), cujo protótipo precisou ser avaliado várias vezes. Nesse sentido, foram ponderados suas complexidades e problemas, no qual culminaram em saberes necessários ao próprio projeto e realizada as devidas alterações. Foi possível compreender os novos aprendizados por meio da experiência ao longo do projeto feito na disciplina, cujo trabalho final foi a criação de um banco como elemento de mobiliário urbano, feito com encaixes de madeira.

\section{Revisão de Literatura}

Segundo os autores Warner e Steger (1995, apud VOLPATO, 2007, p.22), o protótipo é definido "como sendo o resultado do projeto e geração de uma ou mais características do produto que ajudam o pessoal de projeto a testá-las e confrontá-las com os requisitos do usuário." Neste sentido, os protótipos funcionam como uma prévia, a fim de entender seu funcionamento, suas características e sua capacidade de satisfazer o cliente. Os protótipos são bastante associados à aplicação em produtos físicos, mas se refere também a tudo aquilo que é digital, design gráfico e impressão 3D (prototipagem rápida), ou seja, todo produto no qual é pensado para atender às necessidades dos usuários.

O denominado protótipo físico ou visual, "é um protótipo de prova de conceito (às vezes referenciado como protótipo conceitual), utilizado para testar rapidamente uma ideia e realizar 
montagens experimentais (forma e encaixe) de um produto" (VOLPATO, 2007). Normalmente atua como uma das etapas de desenvolvimento de produto, após a geração de ideias e ao desenvolvimento do modelo representativo. Alcoforado et al. (2015) acreditam que "o uso do protótipo dentro do processo de design dá ao design a possibilidade de responder perguntas de forma concreta, materializando conceitos e tornando características tangíveis".

Considerando as etapas lineares no desenvolvimento de projeto, Pahl et al. (2005 apud BRUSCATO et al., 2014), destaca que a primeira etapa do projeto é conceitual, no qual são definidas as soluções e tem como intuito garantir que o produto irá funcionar corretamente como o previsto e de acordo com os requisitos indicados (BRUSCATO et al., 2014). Após a geração de ideias, o designer busca traduzir os conceitos criativos em representações bidimensionais ou tridimensionais, seja no papel ou no computador. Um dos objetivos das representações é auxiliar o projetista a visualizar a solução da melhor forma possível. Assim, a construção de um modelo físico proporciona entender as diferenças entre um funcionamento real e um modelo conceitual (LEMONS et al., 2010).

Com a proposta definida e representada, o projeto poderá prosseguir à etapa de prototipagem. O protótipo possui como objetivo, "verificar experimentalmente se uma proposta deve ser seguida, através da exploração de diferentes aspectos do produto físico como materiais, tecnologias, forma e função" (HALLGRIMSON, 2012 apud BRUSCATO et al., 2014). De acordo com Volpato (2007), ao longo das etapas do processo do projeto, o grupo responsável realiza a tomada de decisões assim como avalia o produto ao longo do percurso. Neste sentido, é importante que haja a análise do protótipo, pois isto poderá levar o designer a lidar com novas perspectivas e refinar o projeto.

O protótipo é a transformação da solução do papel ou do computador em uma experiência tangível, influenciando na mudança de perspectiva do designer. Assim, Buchenau e Suri (2005 apud ALCOFORADO et al., 2015) caracterizam o protótipo em três objetivos: "(1) estabelecer uma compreensão da experiência do usuário ou do contexto, (2) explorar e avaliar as ideias de design e (3) comunicar essas ideias a uma audiência, e em 3 níveis: "look like"(visual), "behaves like"(comportamento) e "work likes" (funcionamento)."

Por vezes o protótipo não se torna exigido ou considerado, devido a alguns fatores que impedem que o designer utilize a experimentação de maneira aprofundada, entre eles, o tempo e o valor investido. Baxter (2000) ressalta que "[...] a regra geral no desenvolvimento dos protótipos é: só faça se for necessário, [...] a construção do protótipo consome tempo e desvia a atenção do grupo, que poderia estar se dedicando a outras atividades que adicionem mais valor ao produto." Porém, Volpato (2007), traz a prototipagem no processo de desenvolvimento de produto (PDP) como uma etapa fundamental da seguinte forma:

Muitas vezes, a garantia de sucesso comercial de um produto está associada à habilidade da empresa em identificar as necessidades dos clientes e imediatamente desenvolver produtos que atendam satisfatoriamente a essas necessidades. Dentre todas as atividades envolvidas no PDP, a utilização do protótipo físico é essencial para melhorar a comunicação entre os envolvidos no processo, bem como reduzir a possibilidade de falhas e melhorar a qualidade do produto. (VOLPATO, 2007).

O processo de prototipar auxilia na objetividade do produto que é almejado, especialmente quando são feitos nos trabalhos em grupos. Nesse caso, uma boa comunicação além de ser necessária, faz toda diferença, especialmente no que tange aos participantes-projetistas exporem pontos a serem modificados ou complementar uma ideia à outra do grupo. Baxter (2000) afirma que o protótipo dará a ideia geral do produto e no que irá se diferenciar dos seus similares. Em outros pontos, perguntas sobre o detalhamento do protótipo começam a surgir.

Analisar a construção do produto irá servir de feedback aos designers e será imprescindível para especificação da fabricação e instruções de montagem do produto. Se referindo à prototipagem rápida, mas também podendo ser aplicada em outros tipos de produtos, Volpato (2007) afirma que o protótipo "possibilita que a análise de sua forma e funcionalidade seja feita numa fase anterior à produção de ferramental definitivo." É possível que sempre exista ajustes a serem feitos até que o produto esteja nos conformes. Nesse sentido, a prototipagem é necessária de modo que, tudo aquilo 
que falhou ou se aperfeiçoou, serve como um aprendizado para a realização de modificações até chegar no objetivo final.

Dessa forma, é importante relacionar aos conceitos de aprendizagem. As práticas da aprendizagem ativa se aplicam não apenas em caráter educacional, mas em termos de avanço dos modelos mentais do designer ou modelos analíticos de interações fenomenais (CAMBURN et al., 2017). Porém, os autores Alonso, Gallego e Honey (2002 apud BARROS, 2012), baseados em Keefe (1998), trazem a aprendizagem dividida por estilos em que "são traços cognitivos, afetivos e fisiológicos, que servem como indicadores relativamente estáveis de como os alunos percebem, interagem e respondem a seus ambientes de aprendizagem" (BARROS, 2012). Em resumo ao que Barros (2012) coloca, os quatro estilos de aprendizagem são definidos da seguinte maneira:

- Ativo, que valoriza dados da experiência, entusiasma-se com tarefas novas e é ágil;

- Reflexivo, que atualiza dados, estuda, reflete e analisa;

- Teórico, o que é lógico, estabelece teorias, princípios, modelos, busca a estrutura e sintetiza;

- Pragmático, que aplica a ideia e faz experimentos.

Destaca-se este último mais aderente na realização de protótipos. Tanto os designers como projetistas da área de engenharia ou arquitetura, lidam constantemente com a aplicação prática das soluções ou ideias. $\mathrm{O}$ estilo pragmático se adequa bem aos projetistas que precisam de respostas em suas experimentações. Apesar das teorias dos autores acima serem focados em alunos do fundamental e na sua forma de aprender, não há um estereótipo, então direcionam os conceitos para analisar a absorção do conhecimento de cada estilo e cada pessoa. Isto pode se aplicar tanto ao aluno de design quanto ao próprio designer, que ademais, podem se aperfeiçoar naquele estilo que não lhe é comum.

Relacionando o estilo pragmático do projetista experimentador com os conceitos de Schön (2000), o autor destaca que o conhecimento é adquirido através das práticas no desenvolvimento do projeto. O autor ainda afirma que "quando aprendemos a fazer algo, realizamos a tarefa sem pensar muito a respeito, somos aptos a nos impulsionar espontaneamente à realização das tarefas, nem sempre sendo dessa forma" (SCHÖN, 2000 apud DORIGON \& ROMANOWSKI, 2008).

As práticas de projetos envolvem descobertas contínuas, desde as etapas de criação até o produto finalizado. As etapas transformam a visão do designer em refletir sobre o projeto, no que tange às proposições, problemas e requisitos. Cada experimentação pode confirmar ou não os questionamentos encontrados. Envolver-se dessa forma com o projeto, determina o que Schön descreve como "reflexão-na-ação", ou seja, lidar com as incertezas, situações-problemas e sendo o conhecimento revelado a partir da ação do fazer. O designer deve assumir, portanto, novas ações a partir do que foi refletido. $\mathrm{O}$ autor discorre sobre a abordagem da seguinte forma:

Todas as experiências, sejam agradáveis ou não, contêm um elemento de surpresa, quando algo não está de acordo com nossas expectativas, podemos responder à ação colocando a situação de lado, ou podemos responder a ela por meio da reflexão, tendo esse processo duas formas: refletir sobre a ação, examinando retrospectivamente o que aconteceu e tentando descobrir como nossa ação pode ter contribuído para o resultado, ou refletir no meio da ação, sem interrompê-la, chamando esse processo de reflexão-na-ação. Nesse momento, nosso pensar pode dar uma nova forma ao que estamos fazendo enquanto ainda estamos fazendo, portanto, estamos refletindo-na-ação. (SCHÖN, 2000 apud DORIGON \& ROMANOWSKI, 2008).

As experimentações têm como objetivo obter o resultado da ação, conforme o discurso de Schön. Neste sentido, é possível afirmar que "as teorias só podem ser apreendidas por meio de aplicações práticas, e só adquirem significado quando incorporadas durante a experimentação" (FLORIO et al., 2007). O designer deve assumir uma visão crítica e reflexiva ao longo do processo de projeto, buscando entender as situações ou problemas que irá lidar.

A partir da reflexão, é importante determinar ações que poderão considerar ou não tudo aquilo que se questionou. As incertezas do projeto ou como Schön denomina "elemento surpresa" são 
comuns de surgirem durante o projeto, tornando a situação de grande complexidade ao designer. Segundo Schön (2000 apud PEREIRA et al, 2017), a reflexão-na-ação é visto "como o processo de gerar conhecimento enquanto se realiza algo, fazendo surgir novos saberes que influenciarão as ações subsequentes do profissional durante o projeto." O projetista irá refletir tanto sobre a própria prática projetual, assim como durante seu percurso.

Enfrentar os problemas, projetos complexos, prazos curtos e metodologias sistemáticas ou lineares não anulam a necessidade de refletir sobre a ação projetual, mesmo que se alterem constantemente. Cada reflexão que surge, acompanhado de seus esclarecimentos, vão "gerando novos conhecimentos, bem como reorientação dos processos de projeto em função da identificação de novas possibilidades para a solução do problema original. Assim, o ato de projetar pode ser associado à processos de aprendizagem e geração de conhecimentos." (PEREIRA et al., 2017)

Portanto, conforme Volpato (2007), a experiência do protótipo com a aprendizagem pode ser vista por meio das representações físicas. Elas são planejadas justamente para solucionar o projeto, servindo como uma ferramenta de aprendizagem e das decisões a cada iteração que são aplicadas. A busca por representar o produto traz uma prévia diante destes pontos, culminando em decisões de maneira mais exata.

\section{Metodologia}

O artigo tem caráter de pesquisa exploratória, sendo desenvolvido a partir de dois procedimentos para o estudo da temática. O primeiro consiste no levantamento bibliográfico por meio digital e impresso. De acordo com Fonseca (2002 apud GERHARDT \& SILVEIRA, 2009), "a pesquisa bibliográfica é feita a partir do levantamento de referências teóricas já analisadas, e publicadas por meios escritos e eletrônicos, como livros, artigos científicos, páginas de web sites."

Nesse sentido, a revisão dos conteúdos para a temática fora consultada a fim de esclarecer os conceitos quanto à importância da prototipagem, bem como relacioná-los a aprendizagem no que tange a reflexão sobre a prática e como ela irá contribuir ao projeto.

O segundo procedimento foi direcionado ao resultado da experimentação realizada no produto desenvolvido na disciplina de Projeto de Produto 4 no curso de Design da UFC. A elaboração do projeto como um estudo de caso, iniciou-se levando como referência os temas em vigência na disciplina quanto à dinâmica, sistema e complexidade. Relacionando os conceitos ao estudo de caso, a segunda etapa foi subdividida da seguinte forma:

- Foram realizadas pesquisas de campo em praças de relevância histórico-cultural e social na cidade de Fortaleza - CE, feita em grupo com os alunos da disciplina, no qual houve entrevistas com os usuários e estudos observatórios nas praças;

- Definição do conceito e geração de ideias com o grupo;

- Desenvolvimento do protótipo de elemento de mobiliário urbano para aplicação na Praça da Gentilândia na cidade de Fortaleza, sendo esta elaboração utilizada como análise individual para melhor exemplificação na abordagem do artigo.

\section{Resultados e Discussões}

O objetivo da disciplina de Projeto de Produto 4 foi desenvolver a partir do design colaborativo, um projeto envolvendo os requisitos: ser um elemento urbano, itinerante, interativo, lúdico, educativo, conceito de "faça você mesmo" e possível de ser aplicado em praças. Com a disciplina sendo construída no sentido de metaprojeto e co-design, a primeira etapa consistia em pesquisa individual para a elaboração de três artigos a serem publicados no blog criado em conjunto com a turma, no qual deveriam abordar sobre os conceitos de sistemas, dinâmicas e complexidades.

A atividade realizada em seguida trouxe um recorte das praças de relevância histórico-cultural e social na cidade de Fortaleza. A turma dividida em três grupos foram responsáveis de visitar e estudar localidades diferentes, tais como o centro, ao norte e centro-oeste da cidade. O intuito da atividade foi analisar cada espaço e a potencialidade das praças, suas funcionalidades como espaço 
público e realizar entrevistas com os usuários e transeuntes. As informações recolhidas foram avaliadas pela turma, que por fim estabeleceram trabalhar a intervenção na praça da Gentilândia, localizada no centro-oeste da cidade e ocupada pelos universitários que moram nas proximidades. Um dos pontos identificados nas entrevistas quanto a essa praça, foi a necessidade de mais bancos do que a praça dispunha, sendo comum até ver grupos de amigos em que alguns se assentavam ao chão, como mostra a figura 1.



Fonte: Blog do Eliomar - Jornal O Povo (2018)

O passo seguinte foi a elaboração conjunta do brainstorming, abordando o projeto em torno dos requisitos e da temática citados anteriormente. Partindo do que cada aluno desejava realizar, envolvendo os temas, a turma foi dividida novamente, mas desta vez em dois grandes grupos, sendo o primeiro na busca de trabalhar em técnicas de tramas para fazer e instalar uma rede. Já o segundo partiu para o uso das características de encaixes para confeccionar um produto urbano de madeira.

O grupo em específico que autora participou foi o segundo, os encaixes de madeira. Primeiramente, realizou-se um brainstorming mais específico para decidir o conceito do produto e a criação de desenhos que utilizava os diversos tipos de encaixes para a elaboração do produto, o que serviu de eixo para definição de seu formato. O grupo buscou traduzir a sua função por meio de encaixes e de formas geométricas, além de priorizar a fabricação, a montagem e desmontagem. Os conceitos definidos foram o formato do reciprocal frames, design geométrico e formatos fluidos que pudessem ser integrados ao tema do outro grupo, a trama da rede.

Com base nisso, cada integrante trouxe ideias utilizando algumas dessas definições para dar início ao projeto. A escolhida por unanimidade foi o reciprocal frames, que pensados através de palitos de picolé, foi idealizado suas formas de encaixes e como poderiam ser unidas à trama, conforme se verifica na figura 2 abaixo. Houve o estudo da forma, sua perspectiva e desenho tridimensional utilizando o plug-in Grasshopper, do software Rhinoceros para definir os parâmetros e precisões dos encaixes, de acordo com a figura 3. Além disso, outro objetivo foi determinar os cortes feitos na CNC (Comando Numérico Computadorizado) da oficina digital do departamento da UFC.

Figura 2 - Teste do reciprocal frames com palitos de picolé.

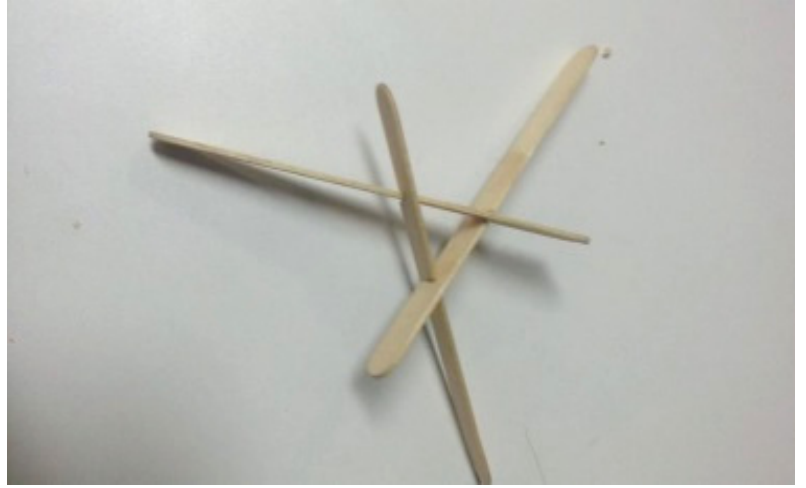

Fonte: Elaborado pela autora, com base na pesquisa realizada (2015) 
Figura 3 - Parâmetros realizados pelo plug-in Grasshopper, no software Rhinoceros.



Fonte: Arquivos colaborativos dos alunos da disciplina (2015)

Nas primeiras experimentações, o corte foi realizado apenas na $\mathrm{CNC}$, utilizando-se três pedaços retangulares de madeira de paletes, de acordo com a figura 4, porém não se encaixavam devidamente. Após mais ajustes e estudos de cálculos, novamente ocorreu um teste na madeira já utilizada antes, mas dessa vez manualmente, com o uso de ferramentas como serra e lixas. Contudo, sem sucesso, as ferramentas causaram danos e a quebra de um dos retângulos. A intenção, prioritariamente, era conseguir o encaixe para depois definir o que poderia ser feito a partir dele. Porém, diante das dificuldades e o prazo curto para o fechamento do projeto, logo se foi eliminando a ideia de integrar à trama e então focando apenas em encaixar as partes necessárias.

Foi usado mais um retângulo de madeira de paletes para perfazer outra tentativa para o funcionamento dos encaixes no protótipo. Após um estudo mais aprofundado de cálculo de angulação dos encaixes, identificou-se que os cortes precisavam continuar a serem feitos manualmente. Todavia, os cortes foram feitos e lixados, mas igualmente não funcionaram.

Figura 4 - Prototipagem com retângulos de paletes pela CNC (à esquerda)



Fonte: Elaborado pela autora, com base na pesquisa realizada (2015)

Os protótipos realizados na $\mathrm{CNC}$ e manualmente cujas necessidades eram de precisão no encaixe, serviram de aprendizado para as etapas que seguiram. $O$ grupo não se deteve na complexidade dos problemas que surgiram e após avaliar que não haveria tempo e estratégia suficiente para continuar o conceito de reciprocal frames, utilizou-se uma das ideias propostas no início no brainstorming do grupo, que seria um banco modular. Ela consistia em um banco de madeira com design geométrico e suas junções dependiam apenas do próprio encaixe, conforme as figuras 5 e 6 . 
Figura 5 - Projeto alternativo com formas geométricas para o banco de encaixes, feito no Adobe

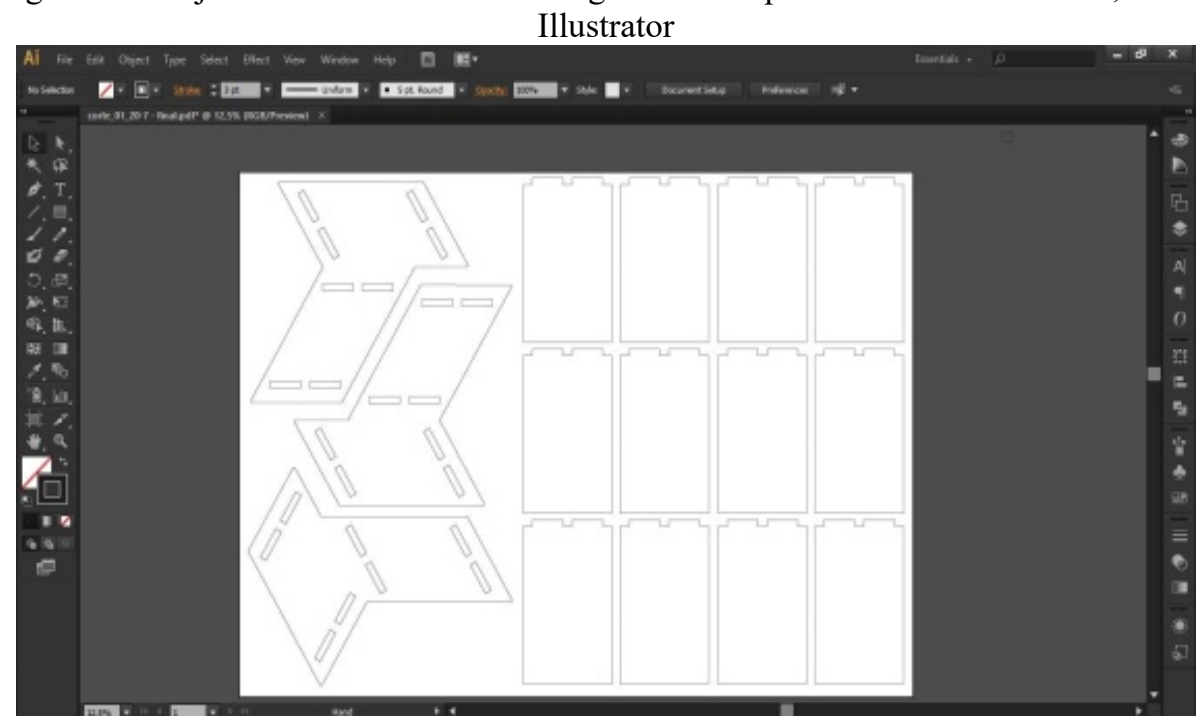

Fonte: Arquivos colaborativos dos alunos da disciplina (2015)

Figura 6 - Projeto alternativo com formas geométricas em modelagem 3D feita no Rhinoceros

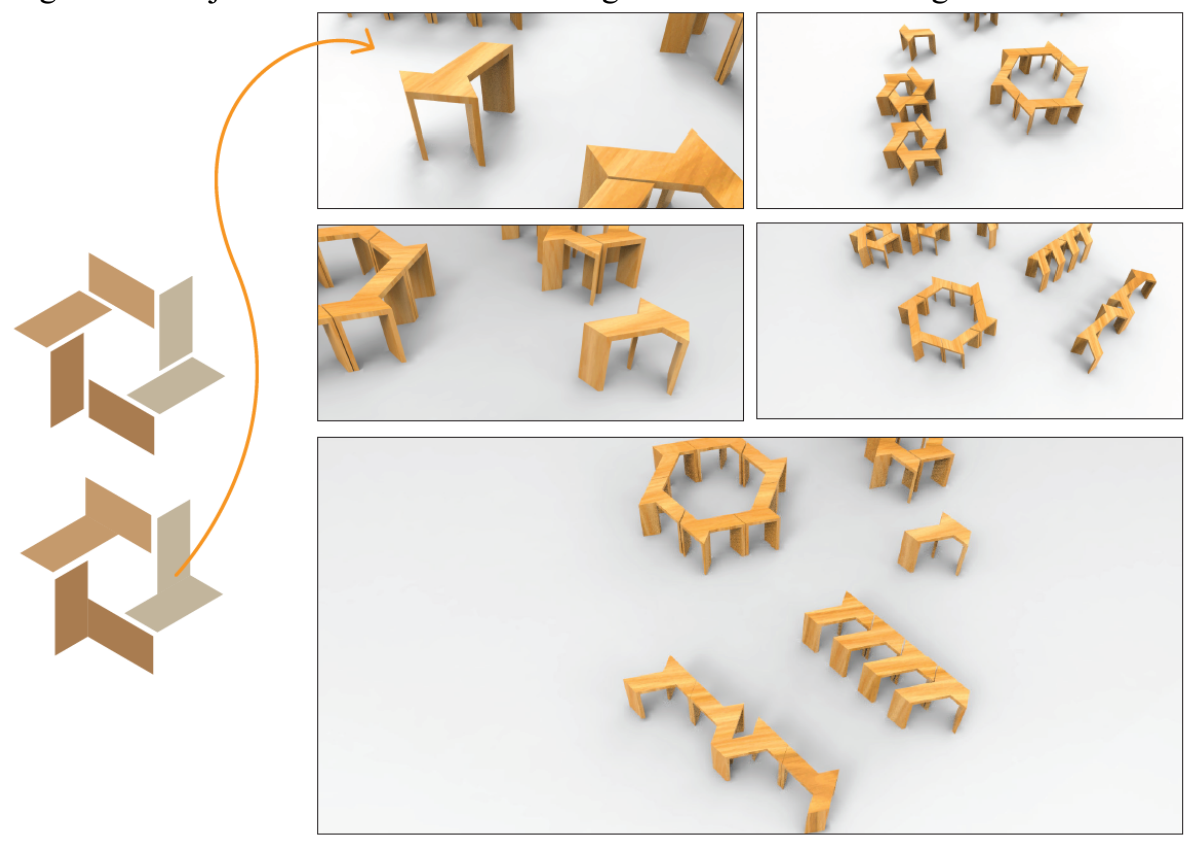

Fonte: Arquivos colaborativos dos alunos da disciplina (2015)

O primeiro teste foi realizado em um MDF cru de $15 \mathrm{~mm}$, ocorrendo diversos testes de precisão nos encaixes. A CNC foi utilizada novamente como ferramenta de fabricação digital. Conforme foi aprendido nos protótipos falhados anteriormente que milímetros de precisão são importantes no encaixe, focalizou-se fortemente neste quesito, a ponto de ser alcançada a elaboração do cálculo definitivo para produção do produto final, visto na figura 7 .

Graças à prototipagem rápida e ao primeiro teste, houve uma atenção maior para as laterais do banco, visto que apresentavam regiões pontiagudas e perigosas ao uso público, sendo então reajustado no desenho digital para formas mais arredondadas. Na produção definitiva do banco de mobiliário urbano, utilizou-se a madeira de compensado naval de $20 \mathrm{~mm}$, devido ao fácil manuseio, textura e sua adaptabilidade de uso em ambiente externo, como praça, no qual seria exposto e teria risco de receber umidade. Além disso, para o acabamento, houve o lixamento manual do produto. 
Figura 7 - Teste de milimetragem de encaixes na CNC para a prototipagem.



Fonte: Elaborado pela autora, com base na pesquisa realizada (2015)

Através da análise do processo da prototipagem realizada, observou-se o aprendizado proporcionado pela experiência na construção do projeto. Um dos preceitos que foi pensado no desenvolvimento do projeto é baseado em Baxter (2000), ressaltando que "o protótipo geralmente é construído com os mesmos materiais do produto final e tem os mecanismos necessários, que o fazem funcionar. Dessa forma, são usados nos testes funcionais do produto." O grupo buscou utilizar materiais simples para os primeiros modelos, mas em seguida usou o material definitivo para dar uma solução mais assertiva ao produto esperado.

A partir do desenvolvimento do protótipo virtual, a fabricação digital e protótipo manual apresentados, cujas necessidades eram de precisão no encaixe, identificou-se a importância da realização de protótipo, o uso das técnicas de prototipagem adequadas, os ajustes ergonômicos e o prazo como contribuições ao processo de projeto. Milímetros de precisão fizeram a diferença para o encaixe correto, contudo, mais que isso, com as falhas dos testes do reciprocal frames, surgiu um olhar mais crítico para a forma de aprender através do processo de prototipagem.

De acordo com os estudos recentes dos autores Camburn et al. (2017), os objetivos comuns encontrados na realização de uma prototipagem, podem ser definidos como refinamento do design; a comunicação como base de valor para o compartilhamento das ideias e informações tanto dentro do grupo bem como aos usuários; a exploração como busca processual e constante de conceitos novos de design; e por fim, a aprendizagem ativa como o processo de obter novos saberes sobre o design e fenômenos importantes. Nesse sentido, por meio do projeto apresentado, foi compreendido que protótipos auxiliam na geração de ideias (antes, durante e após a prototipagem), nos testes com o usuário, o prazo de entrega, na verificação de requisitos, melhorias e feedbacks de projeto. Além disso, a boa comunicação entre os membros do grupo foi primordial para identificar os erros e realizar as melhorias possíveis. $\mathrm{O}$ resultado final do banco de mobiliário urbano se encontra na figura 8 .

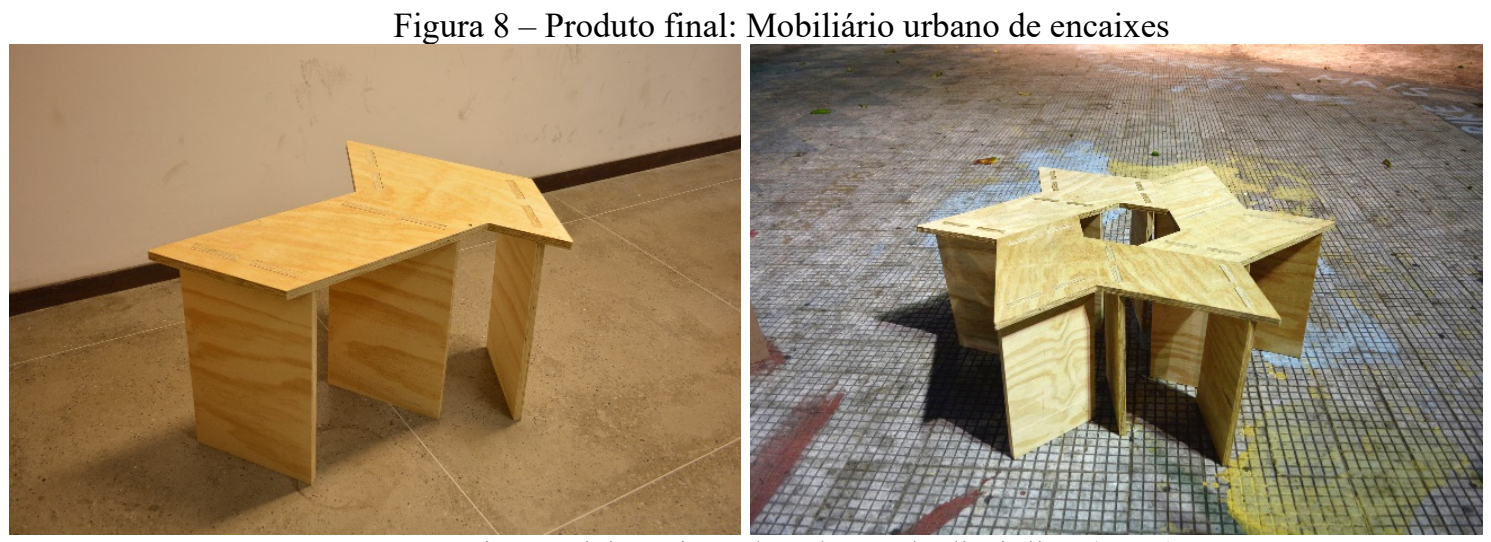

Fonte: Arquivos colaborativos dos alunos da disciplina (2015) 


\subsection{Infográfico gerado com base nos resultados do projeto}

O processo aprendido com o projeto final do banco e sua integração com a disciplina paralela de Projeto Gráfico 4, serviram de base para a elaboração de um infográfico no qual retoma a prototipagem como uma ferramenta de aprendizado. A partir disso, foi desenvolvido um conjunto de passos consideráveis para se realizar e avaliar um protótipo.

Por ter caráter de trabalho acadêmico de projetos, a elaboração do passo a passo descrito teve como motivação servir de orientação complementar aos estudantes de Design, que muitas vezes se deparam com o prazo curto de entrega de projeto, limitações nos materiais, erros de prototipagem, que por fim os levam a refletir sobre suas ações e aos esforços de realizar modificações.

O objetivo do infográfico foi apresentar um caminho no qual pode ser eficaz para os estudantes de Design que muitas vezes não sabem quais passos seguir para a realização de protótipos, principalmente quando os mesmos encontram surpresas ao longo da execução do projeto. Muitas vezes, os protótipos são essenciais na experiência psicológica do designer, para reavaliar o erro como uma oportunidade para aprender, e elevar o sentimento de progresso (GERBER \& CARROLL, 2012). Assim, é preciso que o estudante enxergue que erros ou acertos nos protótipos ainda continuam sendo de total proveito para o processo de elaboração do projeto e até mesmo para outros.

Lim \& Stolterman (2008) afirmam que os protótipos são fundamentais para que os designers ou estudantes de design "aprendam organicamente e evolutivamente, como descobrir, gerar e refinar projetos. Eles são facilitadores do design thinking profundamente adaptado e imerso na prática de design e não apenas ferramentas para avaliar ou comprovar sucessos ou fracassos de resultados de design." São feedbacks que todo designer necessita para executar um bom design e que através deles, o conhecimento é enriquecido. As constantes avaliações auxiliam tanto os projetos atuais quanto aos futuros. O resultado do infográfico pode ser visto na figura 9 abaixo.

Figura 9 - Infográfico sobre o aprendizado através do uso de prototipagem em projetos

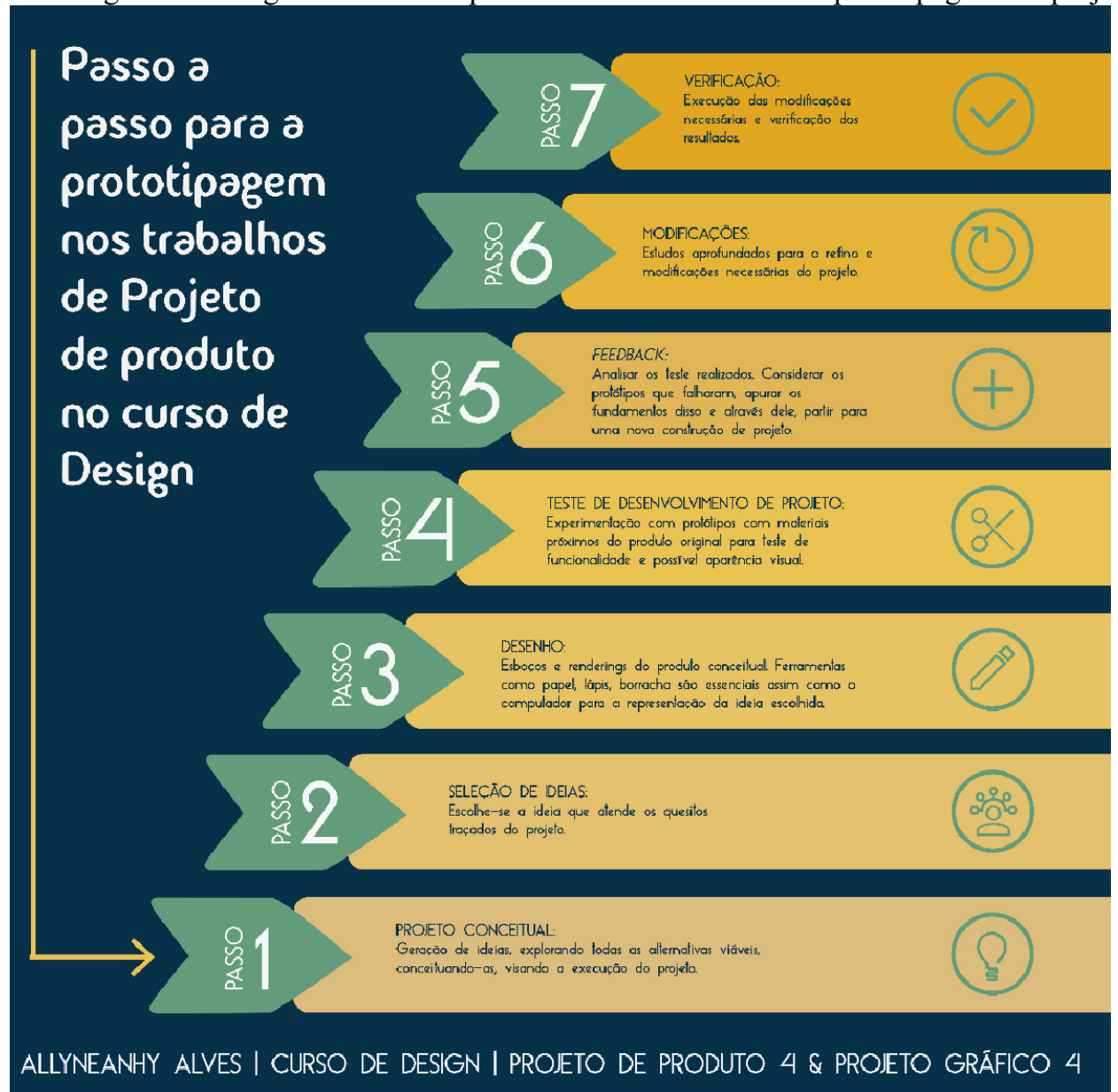

Fonte: Elaborado pela autora, com base na pesquisa realizada. (2015) 


\section{Considerações finais}

No desenvolvimento de projetos, a prototipagem é acompanhada por etapas que segue a ordem de experimentação de materiais, teste de protótipos, análise dos protótipos (feedback), modificações e verificação do modelo. $\mathrm{O}$ processo continua até que sejam alcançados os requisitos necessários. $\mathrm{O}$ feedback é obtido de forma mais conclusiva quando há experimentação dos componentes envolvidos. $\mathrm{Na}$ prototipagem uma diversidade de fenômenos ocorre, inclusive erros e acertos, e dessa forma envolvem o designer pela aprendizagem. Isto efetivamente ajuda o produto a ser aperfeiçoado. Mesmo que não haja sucesso e/ou que haja apenas um teste de modelos ou protótipos, toda experimentação realizada se torna favorável ao projeto.

Trazer os conhecimentos quanto à prototipagem bem como sua relação com a aprendizagem, tornou o estudo do artigo mais embasado. Além disso, a experimentação no estudo de caso demonstrou com sucesso a abordagem da temática, devido a diversidade de testes, reflexões sobre as ocorrências no projeto, as modificações realizadas e o aprendizado adquirido por meio disso.

Com base na prototipagem feita no projeto exposto, houve a verificação na mudança da tomada de decisões, cumprindo os padrões estabelecidos em um curto prazo. Foi observado que experiências como o projeto descrito, expõem a possibilidade de moldar métodos, através das ideias na etapa de brainstorming e as alterações que os testes de prototipagem acarretam. Além de contribuir com novos aprendizados aos participantes do grupo, progrediu-se a uma inovadora solução de projeto.

Portanto, cada designer se adapta aos caminhos, sejam lineares ou sistemáticos, no qual o processo de projeto o leva ao longo da prototipagem de seu produto. Com isso, é importante alinhar as ideações com as práticas do protótipo, de modo que sempre irão gerar reflexões (na ação) quanto a tudo que foi realizado. Cada reflexão gera uma nova tomada de decisão, assim como cada incerteza ou situação-problema encontrado, servem de aprendizado.

Por fim, com esse artigo demonstrou-se o uso da prototipagem como ferramenta de aprendizado, em que os fenômenos ocorridos contribuíram sobremaneira para as mudanças no produto. Além disso, espera-se incentivar aos designers e estudantes de design a olharem para as experimentações de projeto sob essa perspectiva, sabendo que os protótipos proporcionam aprendizados que melhoram os projetos e complementam seus conhecimentos tanto no sentido educacional como profissional.

\section{Reflections on learning through prototyping in product design}

Abstract: Prototyping realizes the role of contributing to the designer's learning, since through this stage, there is great evolution in the project. A designer or design's student often gets an immediate response on their projects, hoping that prototypes will be executed perfectly, but they get frustrated because they usually don't as expected. In this way, this article reflects on the learning obtained through prototyping in product design, amidst the diverse phenomena that occur during the process. For contribute to the study, it is presented the work developed along the discipline Product Project 4, of the bachelor's degree in Design, which represents the exemplification of the theme: the urban furniture project. The results discussed in the article led to the conclusion that the phenomena that occurred in prototyping lead to new information to be considered and that mold the necessary decisions for the project, obtaining its requirements.

Keywords: Prototype; Project; Learning; Design 


\section{Referências bibliográficas}

ALCOFORADO, Manoel Guedes; PASCHOARELLI, Luis Carlos; SILVA, José Carlos Plácido da; "METODOLOGIA CENTRADA NOS PROTÓTIPOS: UM CAMINHO PARA INCLUSÃO DE USUÁRIOS NO PROCESSO DE DESIGN", p. 878-893. In: Anais do $\mathbf{1 5}^{\circ}$ Ergodesign \& Usihc [=Blucher Design Proceedings, vol. 2, num. 1]. São Paulo: Blucher, 2015.

BARROS, Daniela Melaré Vieira. Estilos de aprendizagem e as tecnologias: guias didáticos para o ensino fundamental, 2012. Disponível em: https://www.agrinho.com.br/site/wpcontent/uploads/2014/09/2_14_Estilos-deaprendizagem.pdf> Acesso em: 24 mai. 2020.

BAXTER, Mike. Projeto de Produto: Guia Prático para o desenvolvimento de novos produtos. 2. Ed. São Paulo: Edgard Blücher, 2000.

BRUSCATO, Underléa Miotto; PINHEIRO, Rogélio; TEIXEIRA, Fábio Gonçalves; VIARO, Felipe Schneider; SILVA, Régio Pierre da; "PROJETO DE PRODUTO UTILIZANDO PROCESSOS DE MODELAGEM PARAMETRICA, PROTOTIPAGEM E FABRICAÇÃO DIGITAL", p. 2375-2386. In: Anais do $111^{\circ}$ Congresso Brasileiro de Pesquisa e Desenvolvimento em Design [= Blucher Design Proceedings, v. 1, n. 4]. São Paulo: Blucher, 2014.

CAMBURN, B., Viswanathan, V., Linsey, J., Anderson, D., Jensen, D., Crawford, R., Otto, K. and Wood, K. Design Prototyping Methods: State of the Art in Strategies, Techniques, and Guidelines. In: Design Science, v. 3, n. 13, 2017.

COELHO, Luiz Antonio L. (org.). Conceitos-chave em design. Rio de Janeiro: Ed. PUCRio: Novas Ideias, 2008.

DORIGON, Thaisa Camargo; ROMANOWSKI, Joana Paulin. A reflexão em Dewey e Schön. In: Revista Intersaberes, Curitiba, ano 3, n. 5, p. 8 - 22, jan/jul 2008.

FLORIO, W.; SEGALL, M. L.; ARAUJO, N. S. A Contribuição dos protótipos rápidos no processo de projeto em Arquitetura. In: VII INTERNATIONAL CONFERENCE ON GRAPHICS ENGINEERING FOR ARTS AND DESIGN. Anais do Graphica 2007, Curitiba: UFPR, 2007.

GERBER, E. and CARROLL, M. The psychological experience of prototyping. In: Design Studies, v. 33, n. 1, p. 64-84, 2012.

GERHARDT, Tatiana Engel; SILVEIRA, Denise Tolfo (organizadoras). Métodos de Pesquisa. $1^{\text {a }}$ Ed. Porto Alegre: Editora da UFRGS, 2009.

LEMONS, G., Carberry, A., Swan, C., Jarvin, L. \& Rogers, C. The benefits of model building in teaching engineering design. In: Design Studies, v. 31, n. 3, p. 288-309, 2010.

LIM, Y., STOLTERMAN, E. The Anatomy of Prototypes: Prototypes as Filters, Prototypes as Manifestations of Design Ideas. In: ACM Transactions on Human Computer Interaction, v. 15, n. 2, Article 7, 2008.

PEREIRA, Clarissa; FONTANELLA, Luiza; MEYER, Guilherme; NASCIMENTO, Manoela. Uma análise sobre a construção de conhecimentos por meio do desenvolvimento de protótipos. In: Revista SUL Design \u2013 Anais VIII Sul Design Científico, Pelotas, v. 4, n. 1, 2017. Disponível em: <https://periodicos.ufpel.edu.br/ojs2/index.php/suldesign/article/view/12156>. Acesso em: 02 jun. 2020.

SCHÖN, Donald. Educando o Profissional Reflexivo: um novo design para o ensino e a aprendizagem. Porto Alegre: Artes Médicas Sul, 2000.

TELENKO, C., Wood, K., Otto, K., Elara, M. R., Foong, S., Pey, K. L., Tan, U.-X., Camburn, B., Moreno, D. \& Frey, D. Designettes: an approach to multidisciplinary engineering design education. In: Journal of Mechanical Design, v. 138, n. 2, November 2015.

VOLPATO, Neri. Prototipagem Rápida: tecnologias e aplicações. São Paulo: Edgard Blücher, 2007. 